\title{
Splashing around
}

The beautiful, as Victor Hugo wrote in Les Miserables, "can be as useful as the useful... more so even". We certainly know this to be true in science. Although general relativity, for example, as yet has only a small number of useful applications, few would question its tremendous value in inspiring the human mind to seek an elegant and unified description of all physical reality. Pure science may be an obvious engine of technology, yet our fascination with it derives ultimately from its beauty - from its unexpected explanations that often seem so natural, almost obvious, once we've understood them.

If a drop of liquid hits a hard surface at high velocity, it seems natural that it should break apart and splatter, sending out a shower of tiny droplets. Naively, splashing would seem to be an almost unavoidable consequence of fluid physics - of kinematics coupled with chaotic flow and the finite surface tension of any fluid. But the real story of what happens, and why, is more intricate - and, I think many would say, beautiful.

Physicists have studied droplets for centuries, but researchers only last year learned that the accuracy of our intuition depends wholly on the presence of air. Take the air away, and drops hitting smooth surfaces do not splatter; they simply hit the surface, spread and adhere. Under normal conditions, it is the compressibility of air that causes splashing through an instability at the air-liquid interface. The liquid first forms a symmetric crown or corona, before dissolving into a spray of tiny droplets.

This discovery illustrates how crude our understanding remains of most phenomena involving fluids with free boundaries, especially under conditions where the energy is sufficient to drive boundaries towards singularities. This area is still wide open, and our intuition is often an unreliable guide. Even extremely simple experiments can reveal the strong influence of seemingly unimportant factors.

As well as the air, for example, the roughness of the surface also influences the evolution of a spreading droplet after impact. Experiments using high-speed photography reveal a qualitative transition, with increasing surface roughness, between the common 'corona' splashing, driven by airliquid instability, and an entirely different form of 'prompt' splashing

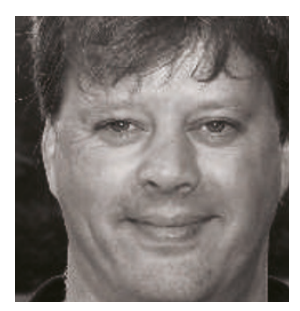

(see Lei Xu et al. http://arXiv/ abs/physics/0608079). Prompt splashing, which occurs even in vacuum, stems from the action of a rough surface in destabilizing an advancing fluid front.

Curiously, prompt splashing continues only for a time, then ceases. This is easy to understand,
THE EMERGING

PICTURE OF WHAT CONTROLS SPLASHING IS AS ELEGANT AND BEAUTIFUL AS THE PHOTOS USED IN UNDERSTANDING IT. $\mathrm{Xu}$ and colleagues suggest, because a rough surface should only perturb a flowing fluid when the size of surface features rivals the fluid depth. This depth for a spreading droplet starts out molecularly thin, but grows with time, hence 'prompt splashing': it starts immediately, but stops when the spreading fluid layer becomes sufficiently thick.

The emerging picture of what controls splashing, and also what determines the size of the droplets produced, is as elegant and beautiful as the photos used in understanding it. The control of splashing is important in industrial processes ranging from the combustion of liquid fuels to spray drying - the means for producing powders in the food or pharmaceutical industries. So, in keeping with Victor Hugo's words, this beauty may well be useful too.

Mark Buchanan

\section{First strike}

Sixty years ago, Albert Einstein said that the existence of nuclear weapons would require humanity to change its way of thinking. Since the bombing of Hiroshima and Nagasaki in 1945, many physicists, including Einstein, have argued that the first use of nuclear weapons can never again be justified. But, with the end of the cold war, the political, if not moral, reasons why initiating a nuclear attack is a bad idea seem to be fading from public and political debate.

For example, of late, one hears talk of developing 'small nukes' that might be used as bunkerbusters, or against enemy troops in battle. This new cavalier approach to nuclear war has prompted groups such as the American
Physical Society to issue statements of concern about the pre-emptive use of nuclear weapons.

It may surprise some that the US has no strict anti-first-use policy. Rather, the US policy, stated in 1995 and reaffirmed in 2002, reads: "The United States reaffirms that it will not use nuclear weapons against non-nuclear-weapon state-parties to the Treaty on the Non-Proliferation of Nuclear Weapons, except in the case of an invasion or any other attack on the United States, its territories, its armed forces or other troops, its allies, or on a state toward which it has a security commitment carried out, or sustained by such a non-nuclear-weapon state in association or alliance with a nuclear-weapon state."

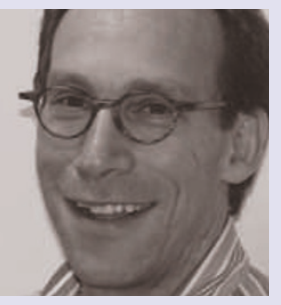

PHYSICISTS MAY HAVE A SPECIAL RESPONSIBILITY

TO HELP

PRESERVE THE

NUCLEAR PEACE.
The loopholes in this policy are large enough to start a nuclear war. The APS has urged a full discussion about the circumstances under which the US might use or threaten to use nuclear weapons, and the consequences for non-proliferation. This seems appropriate. Physicists created nuclear weapons, and although other threats are occupying the public imagination, physicists may have a special responsibility to help preserve the nuclear peace.

Einstein's hope of new thinking in a nuclear world may be too much to expect, but I hope, in these dangerous times, that rational thinking about nuclear weapons is not going out of style. Lawrence M. Krauss 